\title{
The Georgian Caucasus and its resources: the exploitation of the Mount Chikiani uplands during the metal ages
}

Paolo Biagi ${ }^{1, *} \&$ Renato Nisbet $^{1}$

Recent surveys around Mount Chikiani in the Georgian Caucasus have revealed intensive prehistoric exploitation of high-altitude obsidian resources, far beyond the scale previously documented.

\section{Introduction}

Surveys carried out around Mount Chikiani $(2417 \mathrm{~m})$ in the Caucasus of Georgia during 2016 have demonstrated the importance of the unique Bronze Age obsidian mining areas located along the northern slope of the volcano (Biagi et al. 2017a \& b). Further surveys in 2017 discovered a large number of other important features scattered within a radius of approximately $9 \mathrm{~km}$ eastward from the volcano, covering a total area of approximately $45 \mathrm{~km}^{2}$. Although the research is far from complete, the recent discoveries help to define the exploitation of a high-altitude archaeological landscape that extends well beyond the territory suggested by previous fieldwork.

Figure 1 shows the variety and extent of known local archaeological features. These include settlements and burials, kurgans (stone burial mounds) standing both separately and in alignments, basalt quarries and a putative, partially excavated 'fortress' located on Inyak Dağ (2294m asl), a small cinder cone offering strategic views of the local terrain (Narimanishvili \& Khimshiashvili 2009). Also present is evidence for extensive local obsidian working in the form of manufacturing areas and tools (Figure 2) made using obsidian from eight documented lava flows (Nasedkin et al. 1983).

\section{The stone structures}

\section{Kurgans}

Apart from the intense obsidian mining already recorded along the northern slopes of the volcano (Badalyan et al. 2004; Biagi \& Gratuze 2016; Biagi et al. 2017b), an impressive number of monumental structures were discovered and GPS-recorded during the surveys. The most frequent features consist of simple, circular or elliptic stone heaps approximately $2-5 \mathrm{~m}$ in diameter and made of local basalt or andesite blocks, although large obsidian

1 Department of Asian and North African Studies, Ca' Foscari University of Venice, Ca' Cappello, San Polo 2035, I-30125 Venice, Italy

* Author for correspondence (Email: pavelius@unive.it) 


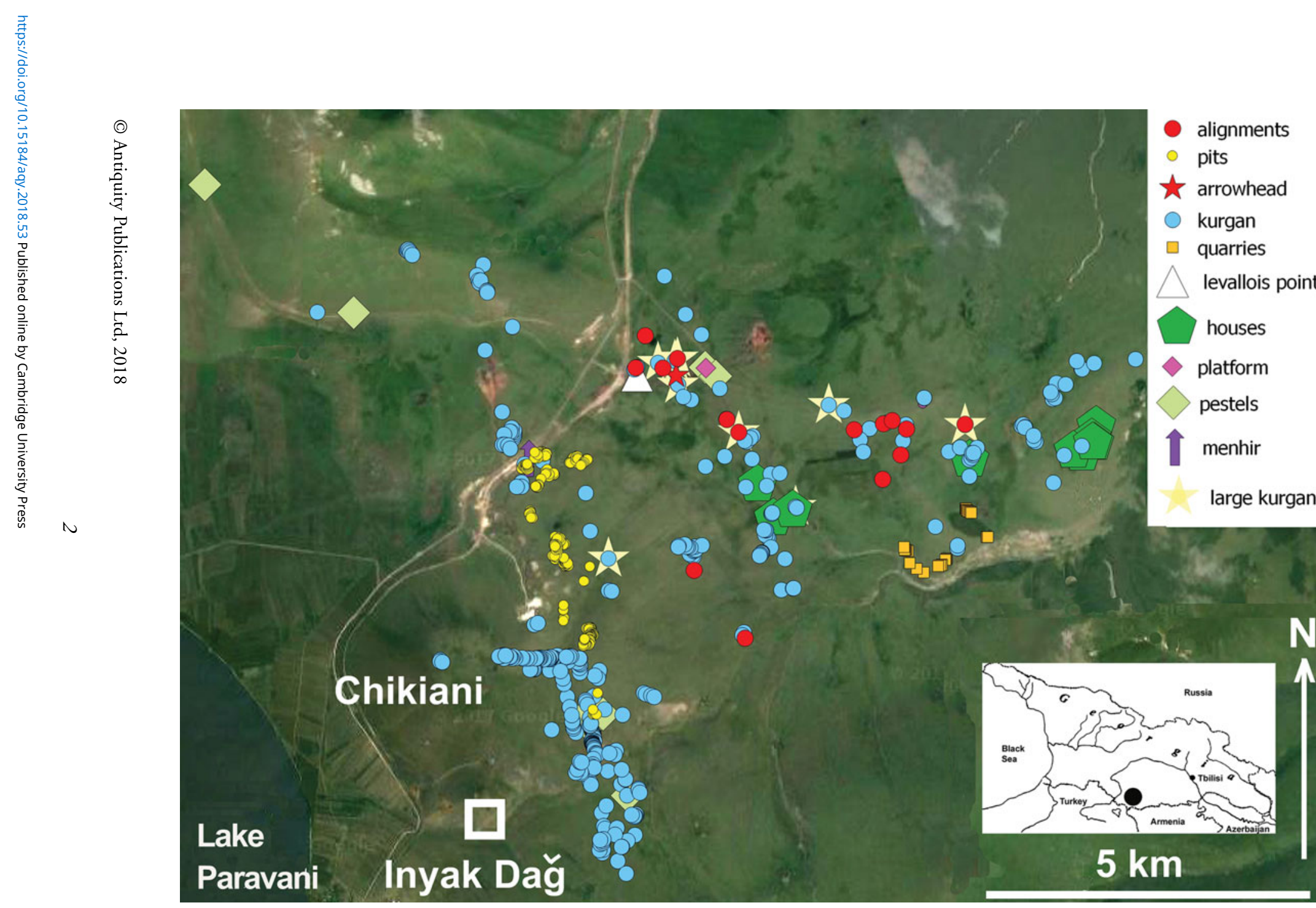




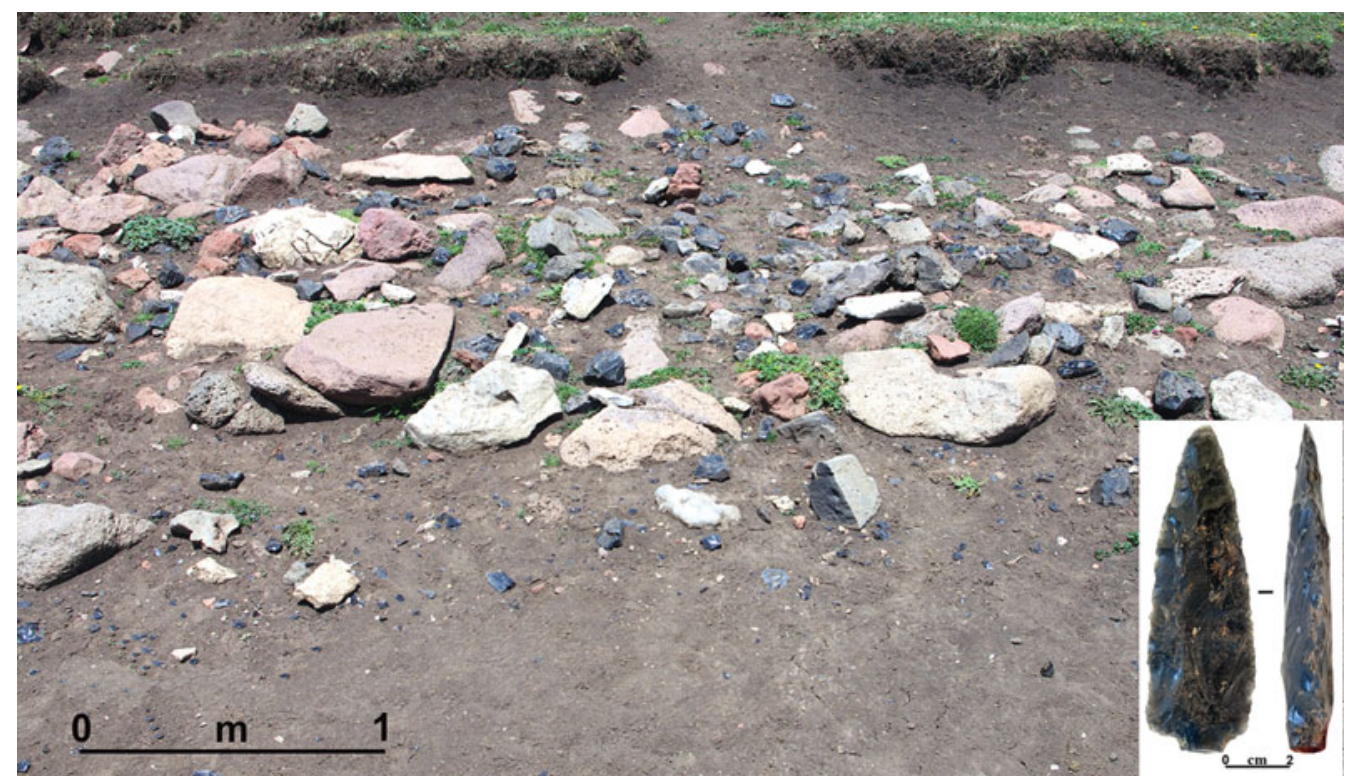

Figure 2. Circular stone platform discovered $7 \mathrm{~km}$ north-east of Mount Chikiani, on which obsidian artefacts were knapped. Inset: an obsidian arrowhead from the same platform (photographs by P. Biagi).

pebbles are also occasionally used. 'Kurgan' may be somewhat inappropriate to define these small stone tombs, considering the complex funerary mounds excavated in the region (Gobejishvili 1980). The word is, however, used here due to their similar burial function.

Kurgans are distributed almost throughout the surveyed area, and represent the most frequently identified (384) stone features. They sometimes form alignments several hundred metres long. More rarely, 'monumental' kurgans occur, complete with one or two causeways marked by stone alignments (Figure 3). These are similar in form to those already known from the Tsalka reservoir (Zischow 2004; Motzenbäcker \& Narimanishvili 2011: 73-84) and to numerous other kurgans in the Trialeti region (Narimanishvili 2010).

\section{Wall alignments}

In contrast with kurgans, long, rectilinear stone structures have no regional comparisons. Most of these structures were discovered in the eastern sector of the surveyed area. They are $70-110 \mathrm{~m}$ long and either north-south or east-west oriented (Figure 4). Very large blockssome well over $1 \mathrm{~m}$ in diameter-were taken from their original location and arranged in one or two parallel rows. No evidence of carving was noted, although a few small obsidian flakes were collected from the bottom of the boulders and from small trial-trenches opened along the sides of the structures.

The structures are probably prehistoric, given the general chronology of the Chikiani archaeological record. The construction methods employed in their creation are not yet understood. How were these boulders transported across uplands and an open, treeless subalpine meadow? Recent coring may offer an insight. Pollen from local cores suggests a spread of coniferous forests well above $2000 \mathrm{~m}$ in the Middle and Late Holocene periods 

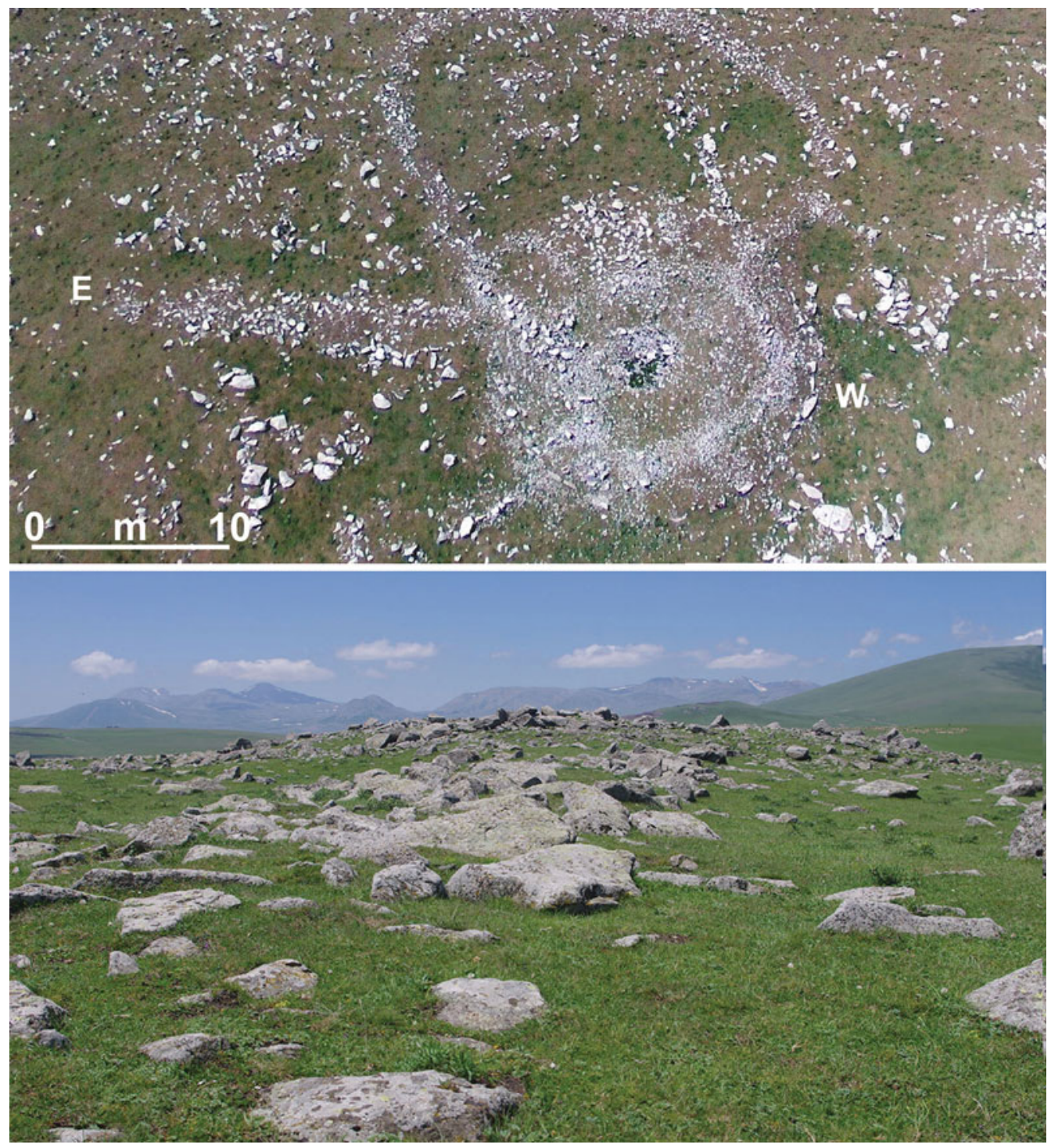

Figure 3. Monumental kurgan K-105 with entrance corridor oriented in an east-west direction, facing north (photographs by M. Ferrandi and P. Biagi).

(Connor 2006; Kvavadze \& Narimanishvili 2010; Messager et al. 2013). These forests may have provided wood for the displacement and transport of boulders.

Other linear features observed near the volcano-of different function to the stone alignments - should be mentioned. Two of these are long linear banks (with ditches), which were probably water reservoirs. The third is a $65 \mathrm{~m}$-long structure, located close to a monumental kurgan (K-128). It is bordered by a causeway-like feature, upon the surface of which were frequently but sparsely distributed obsidian flakes.

(C) Antiquity Publications Ltd, 2018 


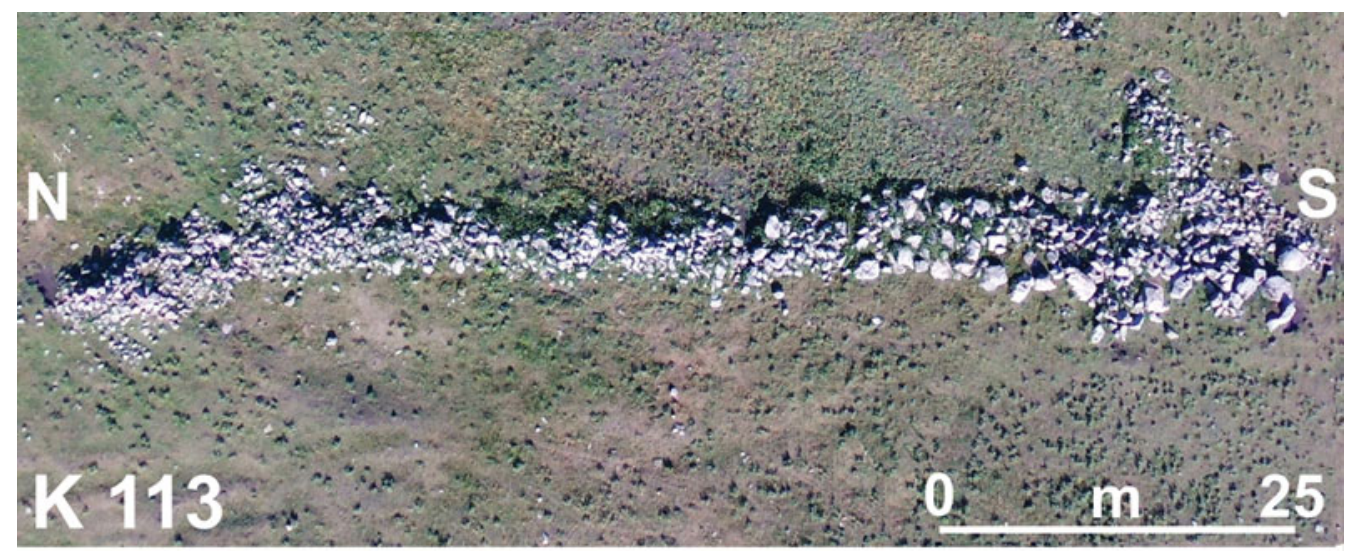

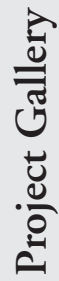
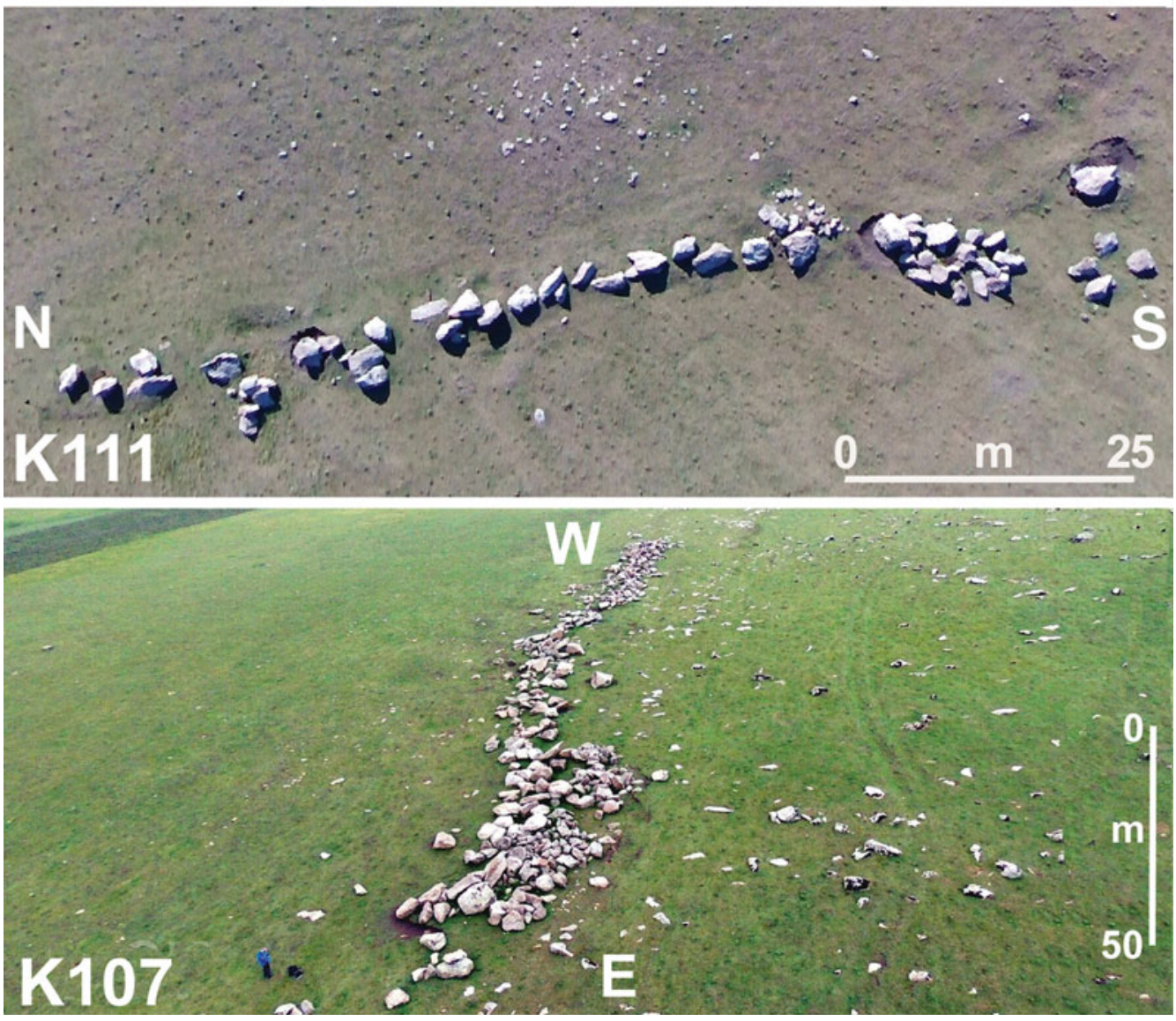

Figure 4. Stone alignments K-113, K-111 and K-107 (photographs by M. Ferrandi).

(C) Antiquity Publications Ltd, 2018 

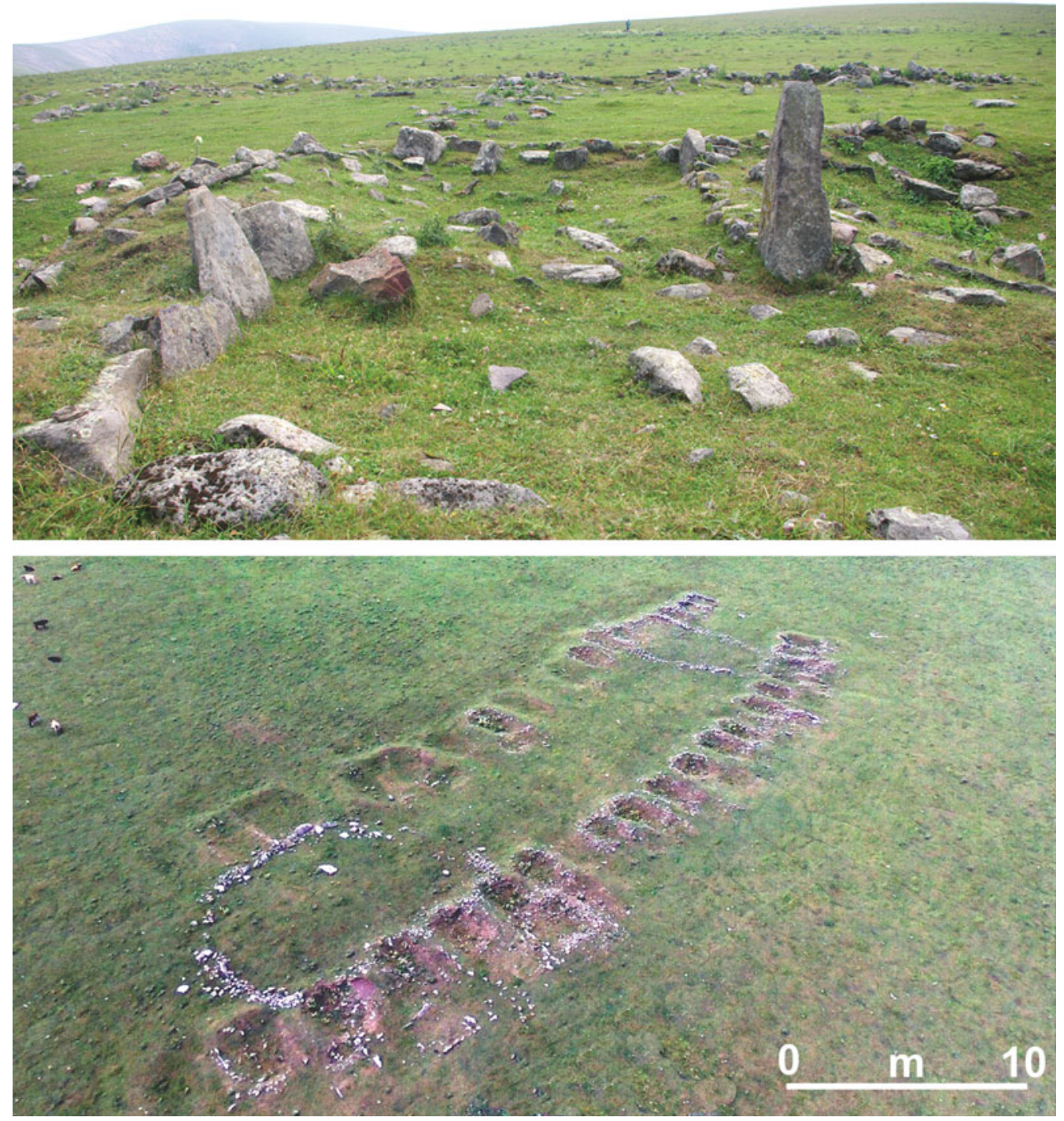

Figure 5. Top: vertical stone structures, slabs and oval corrals; bottom: (top) and villa VIL-6 comprising two parallel rows of apsidal stone structures, facing south-west (photographs by P. Biagi and M. Ferrandi).

A number of clearly more recent enclosures have disturbed older structures and kurgans (Figure 5: top). Abandoned corrals comprising boulder-built square or rectangular rooms are particularly difficult to distinguish from similar prehistoric stone structures.

\section{Settlements}

The most enigmatic features discovered during the survey are concentrated on a terrace facing the steep Chochiani Valley, at the eastern border of the Javakheti plateau. These (C) Antiquity Publications Ltd, 2018 

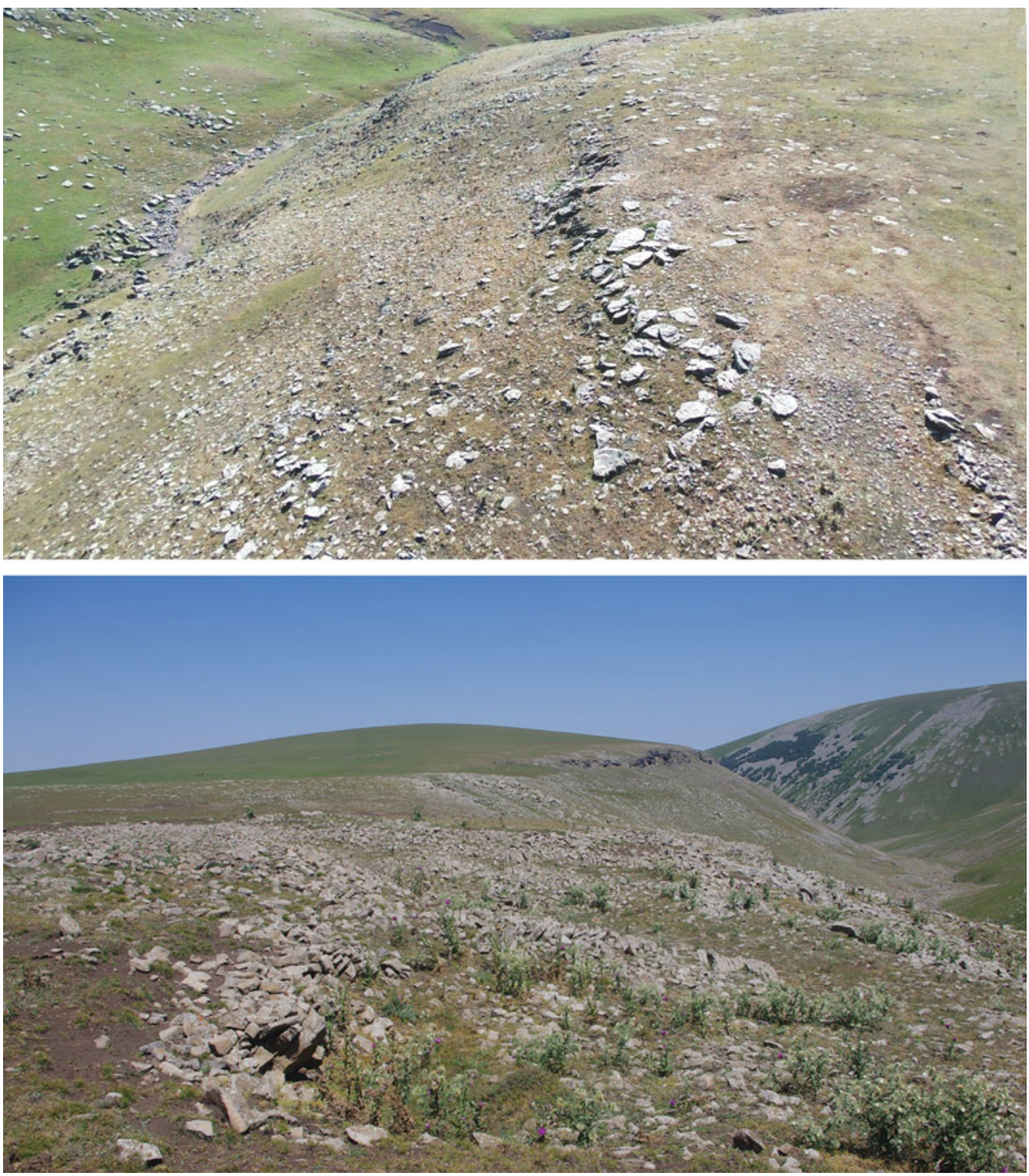

Figure 6. Basalt quarries along the edge of the terrace facing south towards the Chochiani River Valley (photographs by M. Ferrandi and P. Biagi).

features control access to the plateau from the Tsalka. Abundant evidence of basalt quarrying has been recorded along the northern edge of this valley (Figure 6).

\section{Menhir}

An aniconic standing stone (with no evidence of surface carving), approximately $3.5 \mathrm{~m}$ high and locally known as Tikma-Dash, is located along the north-western lower slope

(C) Antiquity Publications Ltd, 2018 
of Mount Chikiani, very close to a group of obsidian mines. In 1940, B. Kuftin excavated some kurgans in this area and dated them to the third millennium BC (Narimanishvili et al. 2015: 215). Although we could not observe the suggested 'snake' carving on its sides (Narimanishvili et al. 2015), we noted the heavily degraded state of the menhir's surface. This degradation, combined with continuous heavy traffic nearby, will shortly threaten the monument.

\section{Discussion}

Bronze Age obsidian mining along the Mount Chikiani slopes involved reshaping the entire territory from the suggested intense use of the local forests through the construction of many kurgans, long megalithic alignments, living spaces and basalt quarries. The chronology of all these upland events remains unclear, and extensive radiocarbon dating is necessary to construct a reliable sequence. The 2016 and 2017 surveys, however, showed the complexity of a region that undoubtedly played a very important role during the metal ages of the Lesser Caucasus of Georgia and its neighbouring countries. This complexity can be attributed mainly to the rich obsidian sources that were mostly exploited during these periods, and whose importance has so far been underestimated.

\section{Acknowledgements}

Thanks go to V. Licheli (I. Javakhishvili Tbilisi State University, Georgia) for his assistance and support for the 2017 survey. The fieldwork was financially supported by Ca' Foscari University of Venice Archaeological Research Funds, and by EURAL Gnutti. We are also wish to thank M. Ferrandi (Ca' Foscari University of Venice) and two I. Javakhishvili Tbilisi State University students who took part in the survey.

\section{References}

Badalyan, R.S., C. Chataigner \& P. Kohl. 2004. Trans-Caucasian obsidian: the exploitation of the sources and their distribution, in A. Sagona (ed.) $A$ view from the highlands. Archaeological studies in honour of C. Burney (Ancient Near Eastern Studies 12): 437-65. Leuven: Peeters.

Biagi, P. \& B. Gratuze. 2016. New data on source characterization and exploitation of obsidian from the Chikiani Area (Georgia). Eurasiatica 6: 9-35. https://doi.org/10.14277/6969-093-8/EUR-6-1.

Biagi, P., R. Nisbet \& B. Gratuze. 2017a. Discovery of obsidian mines on Mount Chikiani in the Lesser Caucasus of Georgia. Antiquity Project Gallery 91(357). https://doi.org/10.15184/aqy.2017.39.

- 2017b. Obsidian mines and their characterization: new aspects of the exploitation of the obsidian sources of Mt. Chikiani (Koyun Dağ) in the Lesser Caucasus of Georgia. The Quarry 12: 2-24.
Connor, S.E. 2006. A promethean legacy: Late Quaternary vegetation history of southern Georgia, Caucasus. Unpublished PhD dissertation, Faculty of Arts, Social and Environmental Enquiry, University of Melbourne. Available at: http://hdl.handle.net/11343/39418 (accessed 9 March 2018).

Gobejishvili, G. 1980. The culture of the Bedeni burial mounds. Tbilisi: Metsniereba (in Georgian).

Kvavadze, E. \& G. Narimanishvili. 2010. The palaeolandscapes of the Tsalka Plateau in the Late Pleistocene and Holocene (according to palynological data from archaeological and geological material), in G. Gamkrelidze (ed.) Rescue archaeology in Georgia: Baku-Tbilisi-Ceyhan South Caucasian pipelines: 582-606. Tbilisi: Georgian National Museum.

Messager, E., S. Belmecheri, U. Von Grafenstein, S. Nomade, V. Ollivier, P. Voinchet, S. Puaud, A. Courtin-Nomade, H. Guillou, A. Mgeladze, J.-P. Dumoulin, A. Mazuy \& D. Lordkipanidze. 2013. Late Quaternary record of the vegetation and catchment-related changes from Lake Paravani (Javakheti, South Caucasus). Quaternary Science Reviews 77: 125-40. https://doi.org/10.1016/j.quascirev.2013.07.011.

(C) Antiquity Publications Ltd, 2018 
Motzenbäcker, I. \& G. Narimanishvili. 2011. Archäologische Ausgrabungen im Dorf Santa (Trialeti, Georgien). Dziebani 20: 73-84.

Narimanishvili, G. 2010. Trialeti in the $15^{\text {th }}$ and $14^{\text {th }}$ centuries BC, in G. Gamkrelidze (ed.) Rescue archaeology in Georgia: Baku-Tbilisi-Ceyhan South Caucasian pipelines: 312-69. Tbilisi: Georgian National Museum.

Narimanishvili, G. \& K. Khimshiashvili. 2009. The Bronze Age settlements from Trialeti, in V. Beridze (ed.) $1^{\text {st }}$ International symposium of Georgian culture. Georgian art in the context of European and Asian cultures: 28-32. Tbilisi: Georgian Arts \& Culture Center.
Narimanishvili, G., N. Shanshashvili \& D. Narimanihvili. 2015. Menhirs from South Caucasus, in M. Işiklı \& B. Can (ed.) International symposium on east Anatolia-South Caucasus cultures: proceedings I: 212-20. Newcastle upon Tyne: Cambridge Scholars.

Nasedkin, V.V., N.N. Sergeev, G. Ya. Alibegashvili \& L.G. RixiladZE. 1983. Geological structure of the Paravani perlite deposit, in Geology and genesis of the most important endogenic non-metallic deposits: 186-98. Moscow: Nauka (in Russian).

Zischow, A.S. 2004. Die Bronzezeitlichen Fundplätze des Tsalka-Plateaus in Trialeti/Georgien im Kontext der Bronzezeit Transkaukasien. Unpublished MA dissertation, Tübingen University. 